\title{
Knowledge in Value Creation Process for Increasing Competitive Advantage
}

\author{
Anna Závodská ${ }^{1}$, Veronika Šramová ${ }^{1}$, Anne-Maria $\mathrm{Aho}^{2}$ \\ ${ }^{1}$ University of Žilina, Slovak Republic \\ ${ }^{2}$ Seinäjoki University of Applied Sciences, Finland
}

KEYWORD

Value creation process

Value innovation

Software engineering

Knowledge

Competitive advantage

\begin{abstract}
The aim of this paper is to compare companies by using value creation model and to determine knowledge in these processes. The framework for the value creation process shows problems of case companies in different phases of this process. Knowledge is compared in each of the individual phases of the process and its role in different types of companies. There is identified role of knowledge for increasing competitive advantage. The methodology involves case study from which data are derived and analyzed. The analysis shows that the framework for the value creation process can be used as an analytical tool for value overview in different phases and there is a need for different approaches to improve business and create new value for customers. Based on the analyzed problems, proposed recommendations for improvement are made. These recommendations are based on providing value innovation for customers (end users of software product). Value innovation of software product is considered as crucial for improvement of the companies in machinery industry. Company A has created new value through remote service. This remote service provides several advantages. Customers can prevent problems in machines by implementing software product which is still analyzing and evaluating data from machines. Company $B$ and $C$ were not able to create major value innovation for several years.
\end{abstract}

\section{Introduction}

This paper is focused on value innovation in different types of companies in order to improve their competitiveness. Three basic elements of knowledge management - people, processes and technologies - were analyzed. Authors mainly focused on analyzing processes which are creating value to companies and knowledge required in them.

Many companies have little awareness about knowledge and ways how to manage it in to get advantage from it. They work exclusively with information pertaining to customers, competitors, suppliers, etc. Authors of this paper see knowledge as something what is very subjective and what is in the minds of employees based on their experiences, skills, beliefs, attitudes and mental models. Tacit knowledge is something what people subconsciously do without thinking about it. They might not be aware of having certain knowledge. Because they do many things subconsciously they might have problem to articulate it. Knowledge in different phases of the value creation process was analyzed and several improvements were proposed.

Three different companies have been chosen for the analysis to show the importance of knowledge in marketing strategy focused on value creation. Two of them were typical consumer companies and one of them was a 
B2B company. Companies were identified as A, $\mathrm{B}$ and $\mathrm{C}$. Each case study is different as is the knowledge they use in value creation process. Companies cooperate with customers in different phases of value creation process: Company A involves its customers in its product development process, Company B and $\mathrm{C}$ cooperate with their customers in operational and post-sale services, but they do not involve them in their product development process. These companies did not have anything in common before the study was carried out. Below is short description of case companies.

Company $\boldsymbol{A}$ is multinational machinery company. The empirical domain of the study is the company's software engineering process, which supplies embedded software in the production machines. Company's headquarters are located in Finland and it has operation all over the world.

Company $\boldsymbol{B}$ is the most popular and biggest seller of consumer electronics in Slovakia. It offers a broad portfolio of products, which include many famous and popular brands. The company was the first that started the wholesales and distribution of electronics of famous brands in Slovakia. The Company has 25 stores all over Slovakia. The present study focused only on one retail seller in Zilina in the Slovak Republic.

Company $\boldsymbol{C}$ is an international pharmaceutical company which produces and sells a variety of nutritional supplements. It was established shortly after the Velvet Revolution in the Czech Republic. Although it is not a large-sized pharmaceutical company, it has obtained a strong foothold in many European countries during its 20 years on the market. Companies in this industry do not sell products directly to their customers but via pharmacies, and therefore communication with customers is limited. The present study focused on one product for pregnant women.

This paper begins with a brief literature overview. This is followed by the analysis of the value creation process in the different company cases. The subsequent section proposes improvements on how to use knowledge management in value creation process for getting competitive advantage. Next part is focused on recommendations for improvements with description of new product which was created after authors proposed these recommendations.

\section{Material and methods}

Data was collected independently in three companies by three researchers. Case study research was used in all cases. Case studies were built from quantitative data represented by graphs, tables and qualitative data from observations, interviews and workshops. Theory built from case study research was compared with existing definitions in literature and scientific papers.

In Company $\mathrm{A}$ the methodology involves a case study using action research. In data collection, several methods were used: interviews, workshops, modeling of information flows and processes, inquiries and observation. The data was collected over a seven-year period in a machinery company using longitudinal empirical research. Additional data needed to be collected after implementation of remote service product. This data was collected by the analysis of the remote service launching process.

In Company $\mathrm{B}$ data was collected in one retail seller's branch in Slovakia during 1 year. There were used several methods of data collection. The quantitative data were gained from analysis of questionnaire survey. They were supplemented by qualitative data from observations and personal interviews with local managers of this branch.

In Company $\mathrm{C}$ case study was built on the basis of usage of several methods: interviews with managers, expert opinions (doctors) and observation in pharmacies. Content analysis was used for analyzing ideas presented in discussion forums by pregnant women. Comparative analysis was used for comparison of implementation of knowledge management principles in pharmaceutical companies in Japan and Slovakia.

The summary of data collection methods is presented in Table 1. 
Table 1. Summary of the data collection techniques

\begin{tabular}{|l|l|}
\hline & Data collection techniques \\
\hline Case Company A & $\begin{array}{l}\text { Modeling of information flows } \\
\text { Workshops } \\
\text { Interviews } \\
\text { Modeling of processes } \\
\text { Observation }\end{array}$ \\
\hline Case Company B & $\begin{array}{l}\text { Observation } \\
\text { Questionnaires } \\
\text { Interview } \\
\text { Benchmarking }\end{array}$ \\
\hline Case Company C & $\begin{array}{l}\text { Content analysis } \\
\text { Interviews } \\
\text { Expert opinions } \\
\text { Comparative analysis } \\
\text { Observation }\end{array}$ \\
\hline
\end{tabular}

\section{Theoretical background}

To understand value creation process it is important to define value. Value is generally considered to describe either the importance of something or its worth. Value creation is grounded in the appropriate combination of human networks, social capital, intellectual capital, and technology assets, facilitated by a culture of change. By delineating the value creation strategy of an organization using the framework, marketers can clearly define product concepts, a new product key success factor. (Yusof, 2010)

Each business has a unique set of processes for creating value for customers and producing financial results. Kaplan and Norton (1996) found a generic value-chain model, which provides a template that companies can customize in preparing their internal business process perspective. This model encompasses three principal business processes: innovation, operations and post-sale service. In the innovation process, the business unit surveys the emerging or latent needs of customers, and then creates the products or services that will meet these needs. The operations process is where existing products and services are produced and delivered to customers. Post-sale services include warranty and repair activities, treatment of defects and returns, and the processing of payments, such as credit card administration.

Knowledge is applied to create value more effectively. (Ruggles, 1999) By using the value chain we are able to identify competitive advantage. (Porter, 1985)

A firm's competitive advantage depends more than anything on its knowledge: on what it knows, how it uses what it knows, and how fast it can find out new things. (Prusak, 1997) Knowledge is experience, everything else is just information. (Zeleny, 2005) "Having information is not the same as knowing. Not everybody, who read cookbooks, is necessarily a great chef. Knowledge is purposeful coordination of action, not description of action." (Zeleny, 2005) "Knowledge management must be brought onto the marketing scene to improve product development, communication and marketinginformation processes. This allows marketers to apply knowledge more successfully, which will improve the efficiency of internal marketing research, deliver well thought-out products and services, and adopt a more effective customer approach.” (Boersma, 2004)

Managers should first and foremost focus on knowledge from the customer - knowledge residing in customers, rather than focusing on knowledge about the customer, as is characteristic of customer relationship management. Customers are more knowledgeable than one might think. (Gibbert, Leibold and Probst, 2002)

Value is created when company creates competitive advantage for its buyers. A company also has to look for competitive advantage beyond its own value chain to justify its position in the value system. (Porter, 1985)

Kotler (1988) describes the value chain as a comprehensive framework for systematically searching for ways to provide superior value to customers. (Porter, 1985)

Dangerous is when one company has achieved competitive advantage the others will start working to even this advantage or even outrun the company. Development of competitive advantage requires long-term 
planning and constancy to purpose. (Porter, 1985)

Knowledge management has been proposed as a fundamental strategic process and the only sustainable competitive advantage for firms (Grant, 1996; Davenport, 1998). A key to understanding the success and failure of knowledge management efforts within organizations is the ability to identify the relevant knowledge to manage and to extract value out of this knowledge. (Schwartz, 2006)

Research indicates that knowledge and knowledge work has infiltrated deep into the value chain of most businesses (Quinn, 1992). (Schwartz, 2006)

Examples of knowledge-intensive service organizations include consulting, software engineering, law firms, and health care. (Schwartz, 2006)

Knowledge based view presents firms as social communities (Kogut \& Zander, 1992) with the primary role of integrating the specialist knowledge resident in individuals into goods and services, so that organizational capabilities are the manifestation of this knowledge integration (Grant, 1996). (Schwartz, 2006)

Knowledge shapes the firm's core competences (Prahalad \&Hamel, 1990) and therefore determines value creation (Grant, 1996). (Schwartz, 2006)

Tacit knowledge, social knowledge, and complex knowledge are difficult to imitate (Leonard \& Sensiper, 1998; Helfat \& Raubitschek, 2000; McEvily \& Chakravarthy, 2002). Hence, competences based on these types of knowledge cannot be easily duplicated by competitors, and strategies based on these competences are likely to lead to sustainable competitive advantage. (Schwartz, 2006)

Knowledge is at the origin of most improvements in customer value (Novo, 2001; Rowley, 2002). Companies create value by instilling knowledge in products and services (Rastogi, 2003), by applying new knowledge to old problems (and in the process displacing existing knowledge), and by synthesizing discrete kinds of existing knowledge (Hamel, 2000). (Schwartz, 2006)

A firm's capacity for sustained and superior value-creating ability may lie in the richness of its knowledge. (Schwartz, 2006)

The companies should not follow a conventional approach, racing to beat their competition. They should follow a different strategic logic that is called value innovation. They focus on making competition irrelevant by creating a leap in value for buyers and their company, thereby opening up a new and uncontested market space. Value innovation is a new way of thinking about and executing strategy that results in a break from the competition. There are paths by which companies can systematically create uncontested market space across diverse industry domains, hence attenuating search risk. Companies can make competition irrelevant by looking across the six conventional boundaries of competition. The six paths focus on looking across: alternative industries, strategic groups, buyer groups, complementary product and service offerings, functional-emotional orientation of an industry, and even across time. (Kim and Mauborgne, 2005)

\section{Value chain analysis}

Kaplan and Norton (1996) have developed the following framework (see Figure 1.) to depict the value creation process. Following this framework, the need of knowledge in different phases in the value creation process was analyzed. The analysis of the three different case companies indicated that this framework does not work for all companies without modification and the reason is because it does not provide any ideas to improve the companies. The companies are represented by the letters A, $\mathrm{B}$ and $\mathrm{C}$. 


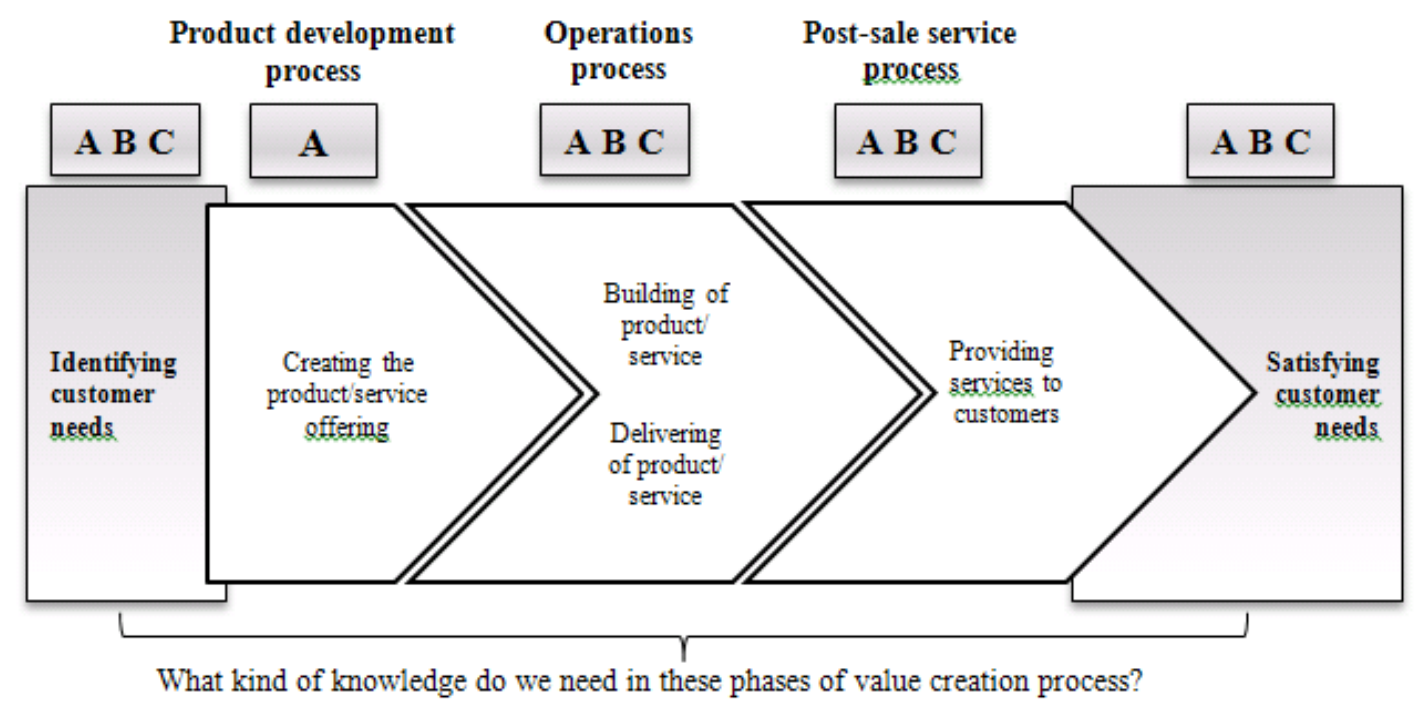

Figure 1. Linkage between knowledge and the value creation process adopted by Kaplan \& Norton (1996)

Identifying customer needs. In Company A's software engineering process, the knowledge about customer needs is derived from sales, project leaders, service and start-up engineers. Although the importance of the customer's role is understood, the customer's role in relation to the software process is quite insignificant. The software engineering process as a part of multidisciplinary product development is not responsible for identifying customer needs. Based on the modeling of information flows, we can conclude that there is no reciprocal interaction between customer and software engineer, and contact is made only when problems occur. Sales have a key role in identifying customer needs in Company A.

Company B identifies customer needs according to market information and knowledge from customers. The parent company collected information about the market, i.e. customers, competitors, suppliers, etc. Based on this information, the company makes a decision about purchasing products for different brands.

Employees of retails were first in contact with customers and their task was to identify customer needs. There is a difference between previous information about market and identifying customer needs by employees: marketers try to estimate future customer needs but sellers need to identify current customer needs at the time when customers come to the retail and want to buy a product. Knowledge about customers was important in the process of identifying customer needs. This kind of knowledge was based on evaluated information obtained through a loyalty program, credit cards and questionnaires, experiences of employees, their skills and attitudes.

In Company $\mathrm{C}$, the knowledge about customer needs was provided by the marketing and sales department. Brand managers endeavored to communicate with customers and gain information in various ways (questionnaires, interview, feedback from hotlines or loyalty programs, etc.), and they sent some of the ideas to R\&D where new products were developed. Direct contact was limited and that was the reason why some products were not successful on the market. Marketers were not able to identify customer needs and because of that products produced were not according to customer needs. Because these products were of a special kind, it was difficult to find out what customers really needed. Usually signals for new products came from the market, from domestic or foreign competitors or findings from international researches. Customers have to buy what the company offers them, not what they really want or need because it might not be possible or not cost-effective to produce it.

It can be concluded that marketing and sales departments play a key role in identifying customer needs. Customer knowledge is very 
important because identifying customer needs and satisfying them is not possible without knowing your customers. Gaining knowledge of customers is difficult, and therefore companies should try to interact with their customers more. Even direct contact in Company $\mathrm{A}$ and $\mathrm{C}$ is not possible, and therefore they should try to obtain the customers' insights as much as they can. Indirect communication often causes many problems when the customers' requirements reach the company too late or in the wrong form so company cannot use them.

Creating the product/service offering. In Company A the use of knowledge was analyzed according to the phases of the software engineering process. Concerning the requirement phase, we can conclude that the main problem in the requirement phase was informality and lack of critical customer knowledge. The project manager has a key role in the process; thus all important customer knowledge in the software engineering process is passed through him. The specifications were quite unclear, which is the consequence of inappropriate knowledge about software features required by customers.

Concerning the phases of design and redesign, most of the information about programming and interfaces was in an extremely informal format and was very subjective. There are no formal procedures or databases. The process involved a lot of tacit knowledge. Some weaknesses regarding knowledge management in the software engineering process are as follows: documentation was not sufficient, contacts to other functions of product development were based on personal characteristics, management of engineering was mechanically oriented, and therefore there was not enough knowledge about time management in the engineering process.

It can be concluded that, overall, communication was incomplete or inaccurate. Very often more information and details were requested. The difficulties were based largely on incomplete documentation and that the need to improve documentation was obvious.

We have identified lack of customer knowledge in the creation of the software product offering.
Building of product/service and delivering of product/service. Company $A$ is providing several machinery products with embedded software which is not trivial. Firstly, the role of software engineering in the machinery industry is changing. Software products are increasingly becoming more important. Traditionally, the product's competitive edge in terms of mechanical engineering is based on the characteristics of the physical product. Today, it is increasingly embedded in software-based products. Software production in a machinery company has a strategic role in the company's competitive advantage. It has shifted from a complementary role to the focus of the product development in machinery companies. Products are customized according to customers' needs. This phase cannot be done without deep customer knowledge which is crucial for company. There is a need to develop process to achieve more detailed customer knowledge in the building and delivering process of the software products. Company B and its retails were not responsible for product development but for building and delivering service, the sale of consumer electronics and installation. The Company offers products from different brands to customers. There are employees whose only task is to create services, and then these services are provided to customers in retails. Each company has a basic package of services which is common in the service industry (e. g. card payment). Companies want to be best in this area and try to develop something special for their customers. Their promotions are often not about products which they are selling but about services they can provide. Nowadays the Company is trying to involve customers in the process of developing services. The customers recognize the importance and appreciate the opportunity to be a part of the team.

Employees can use their knowledge from previous sales situation. The best example of using same knowledge is when an employee serves the same customer more than once. When a new customer comes, the seller needs to use knowledge (s)he already has and connect it to the new knowledge from customer (s)he serves. Using this knowledge is necessary when working with a problematic customer. Many employees find it difficult dealing with these types of customers. Retails have the possibility 
to cooperate together, which enables employees to share key knowledge about processes and help other retails to improve.

In Company $\mathrm{C}$, communication among employees was poor; they did not cooperate. Also, communication with customers was limited because they do not have direct contact with them, only via telephone (customers who call to a hotline) and use information from loyalty programs, doctors, pharmacists or medical representatives. All information goes to brand managers who work with it. Every brand manager receives the information (s)he needs or refers to his/her brand portfolio. Brand managers examined each product category independently without sharing the results with each other.

Knowledge from customers is usually used for marketing purposes, especially in marketing strategy. Customers can help to make effective marketing strategies by giving the company insight into how to market this product. Involving customers can promote the success or cause the failure of a product on the market. Knowledge from customers and employees is important. Employees who hold knowledge about product building and delivering are brand managers, product developers, medical representatives, doctors and pharmacists.

Creating a product according to customer needs is difficult. Customers cannot be involved in the product development process because it may complicate this process (it can increase production costs, confuse product developers because every customer needs something different, brand managers can promise customers ingredients which cannot be in the product, customers may expect outcomes that cannot be promised, etc.). The only phase customers can be fully involved in is the delivering of the product.

Knowledge was also important in this phase. If they know how to gain customer knowledge and also knowledge from their employees, they are likely to succeed on the market. Companies should seek opportunities for development and ways to serve better value to their customers. If they create and deliver products according to customer requirements, customers will most likely buy the products they requested and helped to develop them further.

Providing post-sale services to customers. In Company A it used to be a responsibility of service department. Typical service includes the following phases when there occurs a problem in the customer's machine. In first phase customer makes a service call and after that a technician makes analysis visit to the customer. Secondly, spare parts are ordered and thirdly a technician installs spare part. If the problem is related to the embedded software, the service department contacts software engineers who take care of the problem solving process. We can conclude that in the Company A the software development process suffers the lack of customer knowledge in each phase of value chain. So solution for this problem is remote service.

In Company B, post-sale services start when the customer pays for the products. An example of this kind of service would be the home delivery of a purchased product and the installation of it. Customers know that employees are available for them every time they need them. When a customer has problem with using some type of technology, (s)he can come to the retail and ask or call the helpdesk. Customers expect to be able to purchase additional or spare parts for their product(s) (e. g. cables for a computer, etc.) in the same retail. Employees should know what kind of services customers need and they must be helpful in every situation. Employees should inform customers about spare parts and advise them on how to use a product when they buy it.

Company $\mathrm{C}$ uses knowledge from customers in the phase of providing post-sale services also. They try to take care of customers by providing them with the possibility of becoming a member of their loyalty program. The loyalty program is a very good source of information about customers. Employees can see what kind of products the person has bought and then target their communication directly according to this information. Customers can also call the hotline if they have any problems with the nutritional supplements they took. Company $\mathrm{C}$ tried to interact with customers as much as possible but the problem was that this communication was 
not direct. The Company relies on advice from doctors and pharmacists given to customers. Pharmacists should advise customers on how to use purchased the product(s).

It can be concluded that in both case companies it is important to include customers in the post-sale service phase. In company B, it was easy to communicate with customers and provide the services they needed (installation of products, recycling of old products, membership to the loyalty program, etc.). In company $\mathrm{C}$, it was more difficult to provide this type of service. Brand managers could encourage doctors and pharmacists to advise customers in the purchasing process, they could offer them membership to their loyalty program and encourage them to call hotline when needed. Both companies could provide additional services as a part of their marketing strategy. In these companies, services focus on satisfying customers to keep them.

Satisfying customer needs. According to workshops, the main reasons in Company A for elusive satisfaction of customer needs were due to insufficient information from sales. The reasons for the problem were the overlooking of information or insufficient requirements. In the designing phase, the reason for the elusiveness of complete customer benefit was the emphasis on the wrong issues in the design process. The cross-disciplinary debate in product development was important. In the sales phase, deficiencies in the manufacturing process were sometimes ignored, or unnecessary features were promised by the sales people. The activities carried out in the after-sales phase were essential, e.g. support and training of customers. Better follow-up was required. It is important to invest in production start-up and carefully listen to the customer.

Sometimes at the end of a customer project a new feature or changes had to be added and this created problems in time schedules. This led to a situation where time ran out and the needs of the customer were not fulfilled. The data in the beginning of the project may be incomplete and contradictory. Sometimes complete features may already exist, but due to the lack of a product launch process, the sales department was not aware of these. Also, incomplete testing environments were limited, which led to a situation where bugs were not discovered until customers used the software.

In Company $\mathrm{B}$, it was important to have a variety of products to offer customers. When customers come to the retail, employees should be able to help them find a solution for their requirements. Company B provides approximately 22 services. Employees in retails were responsible for the quality of the services delivered. They were trained in the procedures for providing high-quality services. This company has the best training program for its employees. When a seller does not know any information about a product, (s)he can ask another colleague for help. For this reason, it was important to have a good team. It was necessary to provide high-quality services and after-sales services during the sales process. Customers must feel that employees and the company care about them. A good combination of a product portfolio and services promote success and competitive advantage.

In Company $\mathrm{C}$, the main reasons for the customers' dissatisfaction were due to insufficient information from the marketing and sales department. In the product design phase, the problem could be overlooking information about customer needs, copying competitors without asking customers if they really want this type of product. Production costs play an important role too. There was a lack of crossdisciplinary or cross-department discussion in all of the processes. During the sales process, customers were promised impossible outcomes. There was a lack of information about customers, and doctors and pharmacists usually did not know anything about the products. Exclusive incentives were missing leading to a decrease in the motivation of experts and advisors. There was also a lack of interaction between the marketing department and customers during the product development process. In this area, it was difficult to satisfy all customers, because they requested something different contradictory to their health. The way to satisfy customers in this company was to offer additional value, in the form of services or price strategies, e.g. more tablets for the same price or another nutritional supplement for free.

We can conclude that possible problems of dissatisfaction in different companies can be due to: 
- not identifying customer needs precisely,

- making products that are not requested by market, copying competitors,

- not involving customers in the product development process,

- indirect communication with customers,

- ignorance of customers' suggestions, and

- promising features or outcomes that are not possible.

Customer knowledge is important for value creation. In the phase of identifying customer needs, understanding customer knowledge about product and the services offered is important. In the product development process, customer knowledge needs to be involved to produce products according to customer requirements. Expertise among the software engineers is also important to be able to develop products to meet customer requirements. In the process of creating and delivering products, customer knowledge is important especially in Company $\mathrm{B}$ and $\mathrm{C}$ because this is the only way to implement the customers' insights into improving products and the services associated with these products. Post-sales services are the competitive advantage of Company $\mathrm{B}$ and $\mathrm{C}$. If these companies do not use customer knowledge and do not interact with customers it will lead to customer dissatisfaction. These services provide customers with added value, i.e. they get what they asked for or, more importantly, they get more than what they expected. To satisfy customer needs, companies had to know customer needs and their knowledge about products. Mutual cooperation between the Company and customer and integration of customer knowledge into the process of value creation provides the companies with added value.

\section{Results}

Authors proposed few recommendations for improving value for customers. These recommendations are based on analysis of the value chain. Companies should focus their marketing strategy on creating value innovation for its customers. A tool which can help them to create this value innovation is knowledge of employees, customer knowledge and processes in companies.

Adopting a knowledge-based approach in marketing strategy can create many advantages to an organization. Some advantages of using knowledge in marketing strategy are as follows (Boersma, 2004): ability to identify the most important target groups, increased knowledge about products and services - building the brand and elevating brand perception by increasing brand awareness, ability to bring about product innovation according to customer needs, ability to create and provide targeted value proposition, increased efficiency of the internal processes by using relevant information and reducing information overload, better value to customers by selling products based on customer knowledge, explicit and tacit knowledge from customers optimizes organizational processes.

Based on the analysis of the value creation process, we proposed to create value innovation for customers. Based on our analysis, the Companies were not that successful because they were providing the same products or services as their competitors. Their strategy was about beating the competitors. Innovation chiefly involved technology or services with no accent on delivering higher value to customers. Analysis and research shows that companies have problems with identifying customer needs and if companies do not know what their customers' needs are, satisfying them and providing them with added value is also difficult. The knowledge need was identified in every phase of the value creation process as were the obstacles for better satisfaction of customer needs. This was not enough to create value for customers and keep them. A possible solution and challenge for the companies is to create a leap in value for buyers.

Company A has created this value innovation through new remote service. By developing this remote service product the company can offer added value for their customers and simultaneously get valuable customer knowledge.

This remote service product provides three different services: view, support and efficiency. 
The view part monitors conditions of the machines. The specialists have necessary information from system and this enables specialists to make remote diagnosis for machines. Customers have access to the condition reports via portal. This service includes these partial services:

- condition monitoring,

- condition report,

- specialist analysis,

- JIT service interval,

- safety analysis.

The support service helps to keep up high machine availability by using specialist via remote connection. There is a live picture and Skype connection for on-line communication. For the diagnostics purposes it is possible to record the camera signal in one week cycles. Support includes these main services:

- live camera,

- recorded camera,

- Skype,

- remote connection.

This service enables connection between customer and some technical support via remote desktop application, Skype, chat or camera. The added value is that specialist can be connected with machines remotely. The other new value for customer is 24/7 support. The only requirement for customers is to have camera installed by Company A.

The efficiency tool is used for analysis and improvements of the machines utilisation rate. It gives full reports of the machine run, idle and failure time with the details that enables customers to make necessary actions.

This service is valuable for customers because customers can get crucial information for process analyzing. This efficiency service requires constant monitoring of customers' machines by technicians. The service includes these main partial services:

- production/alarm/idle report,

- utilization rate,

- utilization consulting,

- availability guarantee.

By implementation of the remote service new value was created. Analysis showed that this remote service helped to create competitive advantage for company and also several values customers. Some of the advantages for customers are mentioned below.

\section{Low local stock}

By implementing remote service company can lower its local stock due to flexibility which is this system providing. Company can save inventory costs.

\section{Technicians close to customers}

New system is versatile and allows constant communication and interaction with customers. Due to this flexibility, technicians do not need to spend hours by solving customer problems. They can solve them operatively by connecting to remote information system even in different part of the world. Customers do not need to make any call. Technicians can solve problem immediately. One big advantage of this system is that technicians do not need to travel anywhere when problem occurs. On big advantage which implies from this is that company does not need to have so many multi local skilled technicians.

\section{Preventive maintenance}

The new remote service enables preventive maintenance of the machines. There are more information collected and this machine data are systematically analyzed. All customer machines which have this new remote service installed are monitored by live cameras and specialists analyze camera records and data that system is collecting and updating in customer information system. By this preventive maintenance specialists can automatically find out the problem and react immediately.

\section{Production consulting}

Company is still connected to its customers. Customers can contact support and technicians anytime it is needed. Customers can consult anything they need about their machines. Company can also give advices how customers can run their machines more effectively.

\section{4/7 Support}

There is $24 / 7$ service support available. Customers are from different parts of the world so it is necessary to have this possibility so any customer can reach company at the time they need it. This is providing big competitive advantage in comparison with competitors and previous call service.

\section{Intelligent data from machine}

The new remote service is able to provide intelligent data from machine via software installed in it. This data are analyzed and 
evaluated. Data are intelligent because by analyzing them, managers can get valuable information for production planning and decision making. They can avoid risks by permanent analyzing these data. They can see abnormalities in process and act immediately.

\section{Remote diagnosis}

Remote diagnosis means that technicians are still diagnosing machines remotely. When there is problem with customer machine they can connect to this machine remotely and see problems in it. They do not need to travel anywhere. Big advantage for customer is that technicians can see when something is wrong and meanwhile they can fix it if possible. Remote diagnosis is one of the biggest advantages for companies who have operation all over the world.

\section{Just in time service}

Company offers just in time service. That means that company is able to act operatively and promptly react to customers' requirements. JIT service is appreciated by customers because they do not need to wait for technicians to come to their company but they can solve problems immediately by connecting to their machines remotely. Technicians prevent machine idle time caused by any problem.

Company has made big progress during last years. It became innovative company bringing leading services and big value for its customers. It is leader in remote service products offered to customers in machinery industry.

All mentioned advantages are part of value proposition. They bring competitive advantage to company and added value for customers.

Figure 2. shows differences between company's old situation and new situation after implementation of remote service. After the installation of remote service two steps of the typical process are not necessary anymore: service call from customers when problem occurred and analyze visit to find out the specification of that problem. Optimization of the process brought bigger flexibility in the processes and costs reducing.

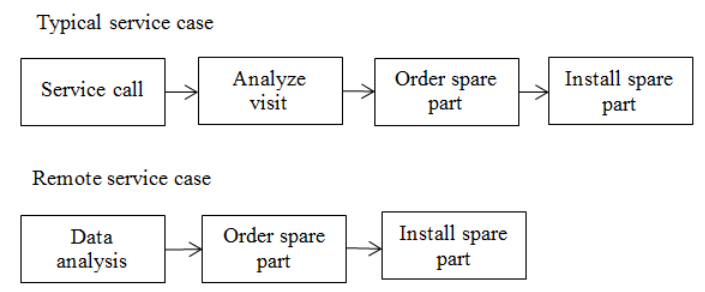

Figure 2. Difference between old and new service

Company B was offered to implement some of the proposed improvements but they did not want to change their retail system. There is problem with enormous change of management, not only local but also top management. Because of this whole internal system is working with problems and it is reflecting inability to change anything and provide value for customers. Company has internal problems and due to this it is not possible to try for improvements and listen to customer needs. If they start to care more about customers, they might come up with some value innovation which would bring them competitive advantage. Major value innovations were: assembly of bought products and taking care of old ones by bringing them to dumps and many kinds of warranties and insurances.

Company $\mathrm{C}$ is innovative company which is still creating new products. But it is not enough because it is not always bringing value to customers. For example company created product for pregnant women but it was not successful on the market. The same has happened to many other products. Company is creating more technological innovation not a value innovation. It does not create value for customers. Recently they created new value to customers by making new multivitamin products which are chewable so customers do not need to swallow big pills. It has fruit taste and it is like jelly. It was a reaction on customers' complaints about size of the pills and also problems with swallowing.

\section{Conclusion}

This article is focused on three companies representing three different industries. There were several internal problems in these companies. The analysis of the value creation 
process in each company was used for comparison. The findings offer insight to what companies should do to improve their business. Companies should not try to beat their competitors but create new business opportunities via value innovation. An analysis of the case studies indicated that the companies should make new values to improve their business rather than using the value creation process alone for analysis. The value creation process is a good tool for mapping value in organization. Companies can see which processes increase value and which do not. They can map their internal processes and see the potential for improvement. Not every company needs to analyze all of the phases of the value creation process. Customer involvement was only possible in some parts of the processes. This framework should be modified by every company or used just as an example of the areas in which value can be analyzed. Having good knowledge in each phase of the value creation process is important but not enough for future success of these companies. When companies work with their customers and use their knowledge in all processes they have a chance to succeed. Companies should stop copying their competitors (being followers) and try to focus on value innovation.

People are most important resources in Software Engineering Company. Software is made by people and their knowledge is added value. By creating remote service in Company A, it is possible to control the machines remotely and fix any problem on the time when it is appeared.

The Company A was the only one which was able to make major improvement and provide value innovation for their customers.

Acknowledgements: This project has been supported by the Slovak VEGA n. 1/0992/11 and 1/0888/11. 


\section{References}

[KAPLAN and NORTON, 1996]

[KIM and MAUBORGNE, 2005]

[MARR, 2005]

[NONAKA, TOYAMA and HIRATA, 2008]

[PORTER, 1985]

[PROSAK, 1997]

[RUGGLES and HOLTSHOUSE, 1999]

[ZELENY, 2005]

[BOERSMA, 2004]

[GIBBERT, LEIBOLD and PROBST, 2002]

[YUSOF, 2010]
KAPLAN R. S. and NORTON D. P. Balanced Scorecard. USA: Harvard College. 1996.

KIM, W. CH. and MAUBORGNE, R., Blue Ocean Strategy. USA: Harvard Business School Press. 2005.

MARR, B., Managing and delivering performance. UK: Elsevier Ltd. 2009.

NONAKA, I., TOYAMA, R. and HIRATA, T., Managing flows - a process theory of the knowledge-based firms. London: Palgrave Macmilian. 2008.

PORTER, M. Competitive advantage. Creating and sustaining superior performance. New York: Free Press. 1985

PROSAK, L. Knowledge in Organizations. UK: Butterworth-Heinemann. 1997

RUGGLES, R. and HOLTSHOUSE, D., The Knowledge Advantage. US: Capstone. 1999.

ZELENY, M., 2005. HSM Integrating Knowledge, Management and Systems. Singapore: World Scientific Publishing Co. Pte. Ltd.

BOERSMA, A., The original knowledge management publication: Did someone say customer?, Inside Knowledge magazine. 2004.

Available at: http://www.ikmagazine.com/

GIBBERT, M., LEIBOLD, M. and PROBST, G., Five Styles of Customer Knowledge Management, And how Smart Companies Put them into Action. 2002. Available at: http://archive-ouverte.unige.ch

YUSOF, S. W. M., Developing Strategy for Customer Value Creation Towards a Professional Services. 2010. Available at: http://webs2002.uab.es/dep-economia-empresa 